\title{
Knowledge,Awareness and Attitude About Preterm Birth and its Causes Among Females of Reproductive Age Group
}

\author{
B.Harini ${ }^{1}$, Dr. M.P. Brundha ${ }^{1 *}$ and Dr .V.B.Preejitha ${ }^{2}$ \\ ${ }^{1}$ Department of Pathology, Saveetha Dental College and Hospitals Saveetha Institute \\ of Medical and Technical Sciences Saveetha University, Chennai -77, India
}

${ }^{1}$ Associate professor, Department of Pathology, Saveetha Dental college and Hospitals Institute of Medical and Technical Sciences, Saveetha University, 162,Poonamallee High Road, Chennai-600077, Tamil Nadu, India ${ }^{2}$ Department of Pathology, Saveetha Dental College and Hospitals Saveetha Institute of Medical and Technical Sciences Saveetha University, Chennai -77, India

\section{ABSTRACT}

Preterm births are babies born less than 38 weeks of gestational age as opposed to the usual about 40 weeks.It is recommended that labor not to be medically induced before 39 weeks unless required for other medical reasons .Preterm birth is the most common cause of death among infants worldwide.So recent attention has been given to mortality and morbidity risk factors associated with moderate and late preterm delivery. Preterm birth not only affects infants but also the mothers. Preterm birth can be caused due to neonatal complications or maternal complications but in some cases it can be both maternal and neonatal complications. The aim of our study is to find out the awareness of preterm births and its causes among reproductive women. So a survey was conducted for a sample size of 100 samples to analyze the awareness about preterm births and its causes among reproductive women.The data was statistically analysed (descriptive and chi square analysis) and the results were interpreted. The P value was From this survey we conclude that there is awareness of preterm birth and its causes among females of the reproductive age group is about average of $65 \%$. The age group 20-30 years females of our study sample were more aware about the causes and complications of preterm birth than the 18-20 years aged group. There are many health related problems which can lead to premature babies or preterm births. Preterm birth can be mainly caused due to stress and preterm birth can be prevented by regular checkup for both mother and foetus, good nutrition and happy surroundings

KEY WORDS: PRE TERM, BIRTH, COMPLICATIONS, AWARENESS, CAUSES.

\section{ARTICLE INFORMATION}

*Corresponding Author: brundha.sdc@saveetha.com

Received 13th June 2020 Accepted after revision 12th August 2020

Print ISSN: 0974-6455 Online ISSN: 2321-4007 CODEN: BBRCBA

Thomson Reuters ISI Web of Science Clarivate Analytics USA and Crossref Indexed Journal

$$
\begin{aligned}
& \text { Clarivate } \\
& \text { Analytics }
\end{aligned}
$$

NAAS Journal Score 2020 (4.31) SJIF: 2020 (7.728)

A Society of Science and Nature Publication,

Bhopal India 2020. All rights reserved.

Online Contents Available at: http//www.bbrc.in/

Doi: http://dx.doi.org/10.21786/bbrc/13.7/23 


\section{INTRODUCTION}

A normal pregnancy is about 40 weeks.Preterm births are babies born less than 38 weeks of gestational age as opposed to the usual about 40 weeks.It is recommended that labor not to be medically induced before 39 weeks unless required for other medical reasons .Preterm birth is the most common cause of death among infants worldwide.About 15 million babies are preterm each year (5\% to $18 \%$ of all deliveries).Approximately $0.5 \%$ of births are extremely early periviable births, and these account for most of the deaths.In many countries, rates of premature births have increased between the 1990s and 2010s.Complications from preterm births resulted in 0.81 lakhs deaths in 2015 down from 1.57 million in 1990.

The chance of survival at 22 weeks is about $6 \%$, while at 23 weeks it is 26\%, 24 weeks 55\% and 25 weeks about $72 \%$.The chances of survival without any long-term difficulties are lower (Iams, no date).So recent attention has been given to mortality and morbidity risk factors associated with moderate and late preterm delivery.As we all know preterm birth is a major challenge perinatal health care.Preterm birth not only affects infants but also the mothers. Preterm birth can be caused due to neonatal complications or maternal complications but in some cases it can be both maternal and neonatal complications.Some obvious reasons for early delivery is medical reason (Goldenberg et al., 2009).

Spontaneous preterm labour is being mainly caused by multiple pathological conditions that leads to $70 \%$ of the world's preterm birth.Among all the neonatal deaths occurring in our developing countries its fate is high in remote areas were preterm babies are born at home and treated.And more women in rural areas have a greater significance of eclampsia than women in urban areas (Lisonkova et al., 2016). Its known that women with very short intervals between pregnancies are at increased risk of complications such as preterm birth,neonatal death,and growth restrictions.And the etiology includes chronic ,catastrophic stress, maternal anxiety,stress which is being mostly affected and leads to premature babies. Preterm births also sometimes include lifestyle factors that favour pregnancy outcomes (Thornton, 2008).It's quite interesting to know that increase preterm birth have increased the chances of twin babies that Inturn decreases the chance of perinatal deaths in twin pregnancies of preterm delivery before 34 week of gestation.

But preterm babies are always low birth weight remain high priority in public health problems and are associated with increased risk of infant mortality as well as long term health impairments (Joseph et al., 2001).Among all the causes recent research that proved the major risk factor is stress,emotional states of the mothers with mental anxiety,depression and adverse health risks. Infections(Brundha, 2015) are likely to be associated with infections ,and may include poor eating habits, drinking and smoking habits that increase the early birth.So more care and attention should be given to pregnant women during their pregnancy time to keep them away from all types of anxiety and any kind of stress that would involve pregnant women (Dietze, Rose and Moore, 2016). In most cases ,preterm labour begins unexpectedly and the cause is unknown still, like regular ,labor, signs are mostly change in vaginal discharge ,pelvic pressure ,low and dull backache ,cramps feeling like menstrual period and abdominal cramps with or without diarrhoea.These include central and peripheral systems implicated in psychological stress(Wadhwa et al., 2011).

As we all know preterm babies are not fully developed, so they may suffer from various complications such as Respiratory distress syndrome,feeding difficulties,jaundice(Abijeth and Brundha, 2017), severe infections,brain injury, necrotising enterocolitis,retinopathy of prematurity and anemia prematurity.The main care should be to stress and amd vulnerability to stress pregnancy (Dole, 2003).Preterm birth babies facing first factor is with low birth weight but those babies are proved to have a smarter brains when compared to babies born full term of gestation .The largest improvement in survival occurs between 25 to 32 weeks (Copper et al., 1993; Benitz, 2009).Preterm birth can be diagnosed by cardio - respiratory monitoring,blood test, fluid input and output,echocardiogram, Ultrasound scan , and eye examination.Preterm birth can be prevented by regular health check ups, healthy eating ,stress free surroundings,enabling early and long term tocolytic therapy (Scott, Steel O'Connor and Carr, 2001)

\section{MATERIAL AND METHODS}

Sample Collection: A questionnaire based survey was conducted for a sample size of 100 samples to analyze the awareness about preterm births and its causes among females of reproductive age group. Nearly 12 questions had been prepared and it was asked to the females of the reproductive age group(15-49 years) in the general population and answers were recorded.

Inclusion Criteria: Selection criteria include females of age between 15 to 49 years.

Exclusion Criteria: Females of age below 15 years and above 49 years and marital status were excluded.

Sampling Method: In the present study,the sampling method used is a random sampling method.

Data Collection and Tabulation: The number of questions distributed was 12.The close ended yes or no type of question were asked.Their responses were entered into the excel sheets and then tabulation of the data finally and the question comparison was done. The representation of the data is through the bar graph .

Statistical Analysis: The statistical software used IBM SPSS V22.The statistical test used is Chi square test ( $p$ value).Type of analysis used were descriptive analysis, demographic data. 


\section{RESULTS AND DISCUSSION}

The results showed that the awareness of term and preterm birth, the month of preterm birth,consequences of preterm birth, causes of preterm birth, complications of preterm birth, preventive measures of preterm birth (Figure 1-11) among the females of reproductive age group is with in an average of 65\%. When we compared the age groups of our study population with the knowledge of causes (Figure 12) and the knowledge on complications of premature birth (Figure 13), we found that the age group 20-30 years females of our study sample were more aware about the causes of preterm birth than the $18-20$ years aged group. The $p$-value obtained was 0.020 $(<0.05)$ and also the majority of the study population aged between 20-30 years were more aware of the complications of preterm birth than the other age group (18-20 years). However the difference was statistically not significant. (P-value-0.976 (>0.05)).

Figure 1: Pie chart shows the awareness about preterm birth where blue colour denotes YESand green denotes NO. 87.72\% of the study participants answered they were aware of the term and preterm births.

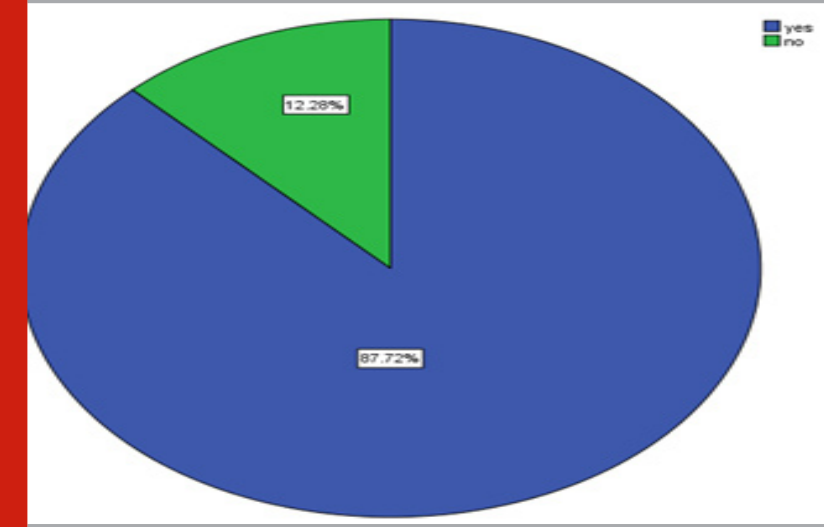

Figure 2: Pie chart shows the preterm birth month where blue colour denotes YES and green denotes NO. 91.23\% of the study participants were aware of the month of preterm babies.

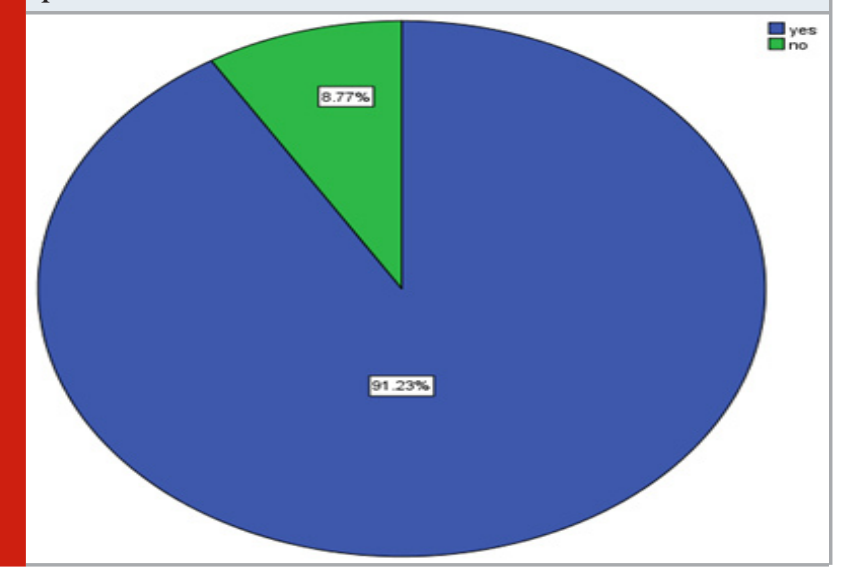

Figure 3: Pie chart shows awareness of mortality rates of preterm birth where blue colour denotes YES and green denotes NO. 56.14\% of the study participants answered that they were not aware of the mortality rates of preterm birth.

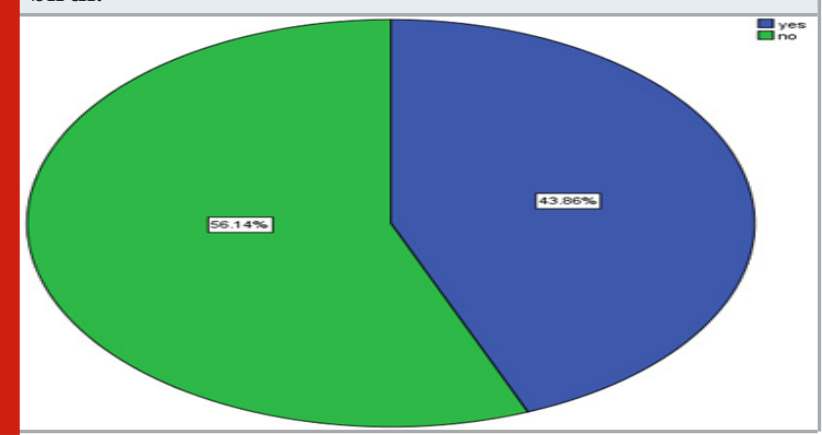

Figure 4: Pie chart shows the awareness of consequences of preterm birth where blue colour denotes YES and green colour denotes NO. $63.16 \%$ of the study participants answered that they were aware of the consequences of preterm birth.

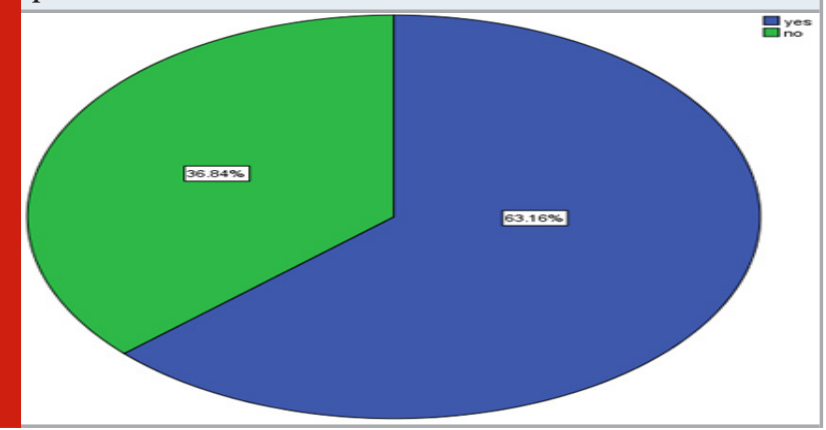

Figure 5: Pie chart shows the causes of preterm birth where blue colour denotes problem with foetus ,green denotes poor nutrition and beige denotes stress. 56.16\% of the study participants answered that the main cause of preterm birth can be problem with foetus.

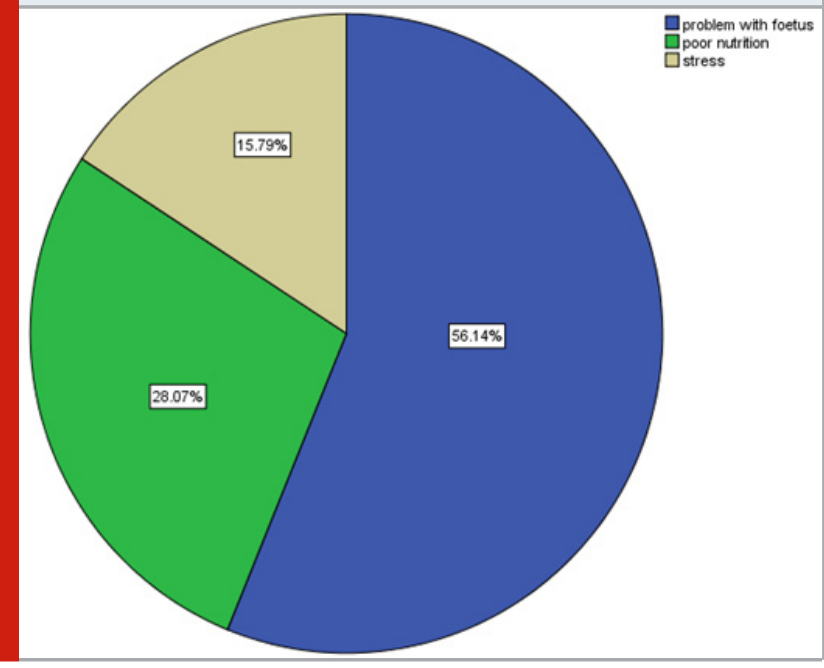


Figure 6: Pie chart shows whether preterm birth is a complication of pregnancy where blue colour denotes Yes and green denotes No. $64.91 \%$ of the study participants answered that preterm birth was a complication of pregnancy.

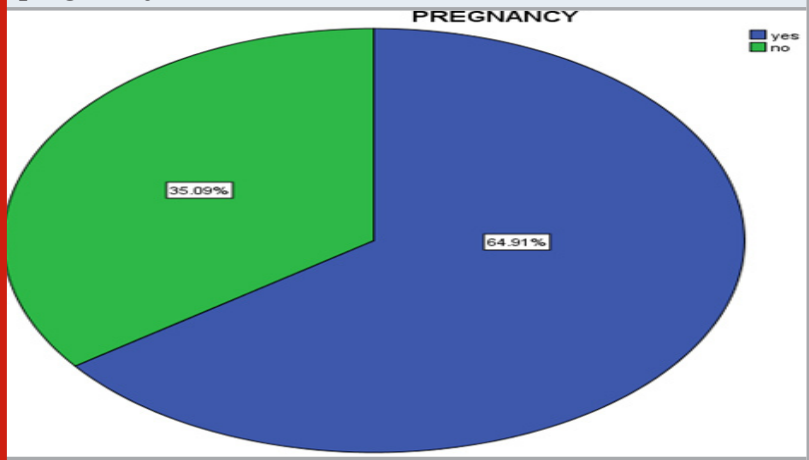

Figure 7: Pie chart shows the preterm birth complications were blue colour denotes maternal complication,green denotes foetus complication, beige denotes both and purple denotes none.52.63\% of the study participants answered that the complication for preterm birth can be maternal complication.

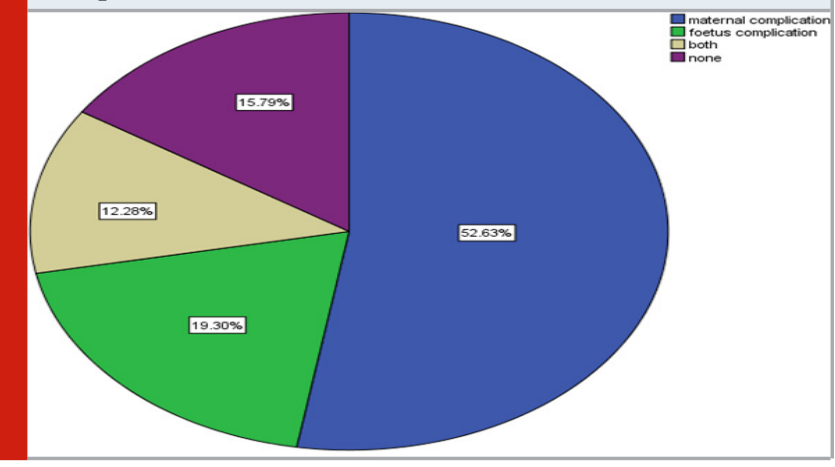

Figure 8: Pie chart shows reason for preterm birth where blue colour denotes Yes and green colour denotes No. $66.67 \%$ of the study participants answered that health related problems can affect premature babies.

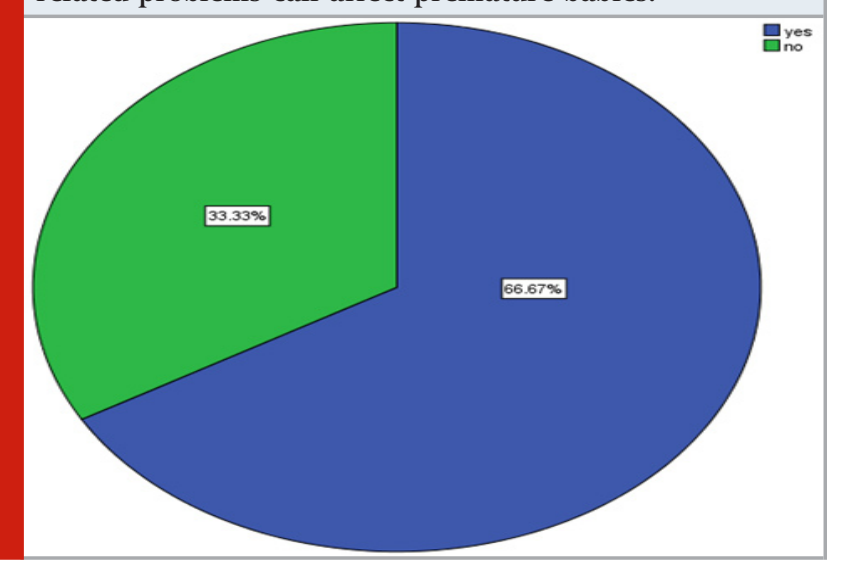

Figure 9: Pie chart shows premature babies are smarter where blue colour denotes YES and green colour denotes NO. $64.91 \%$ of the study participants answered that premature babies are smarter due to faster brain growth.

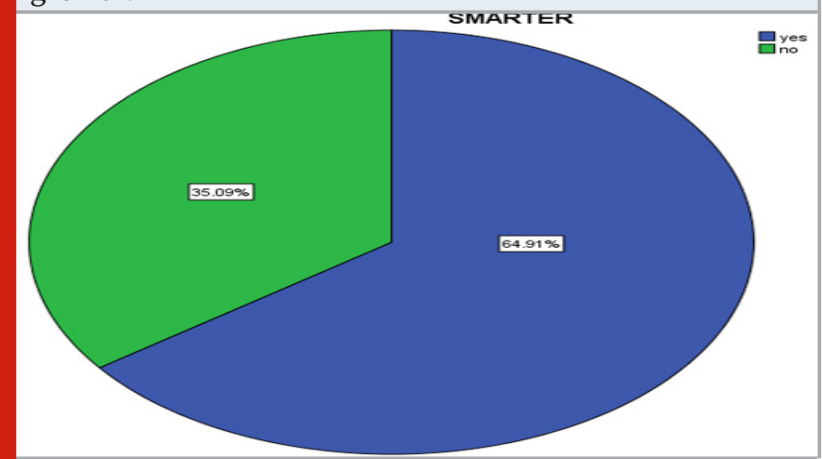

Figure 10: Pie chart shows whether preterm births can be prevented where blue color denotes YES and green denotes NO. $61.40 \%$ of the study participants answered premature birth can be prevented to a certain extent.

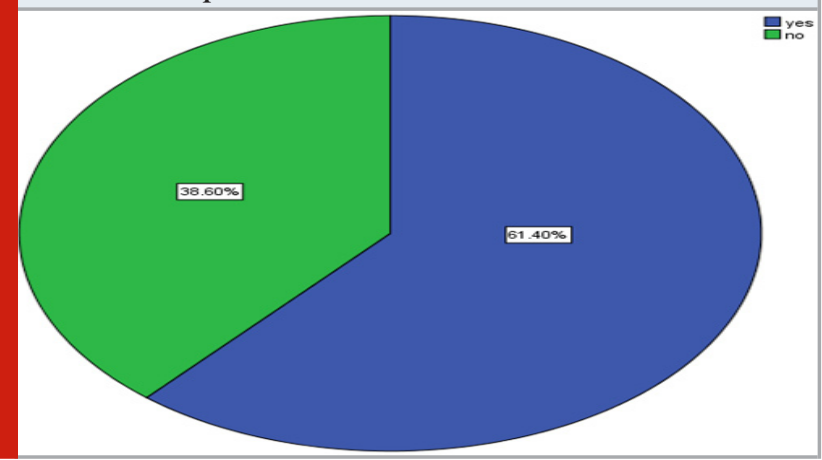

Figure 11: Pie chart shows the various ways preterm birth can be prevented where blue colour denotes proper health education,green denotes good nutrition and beige denotes having a healthy environment. $36.84 \%$ of the study participants answered that promoting proper health education ways preterm births can be prevented.

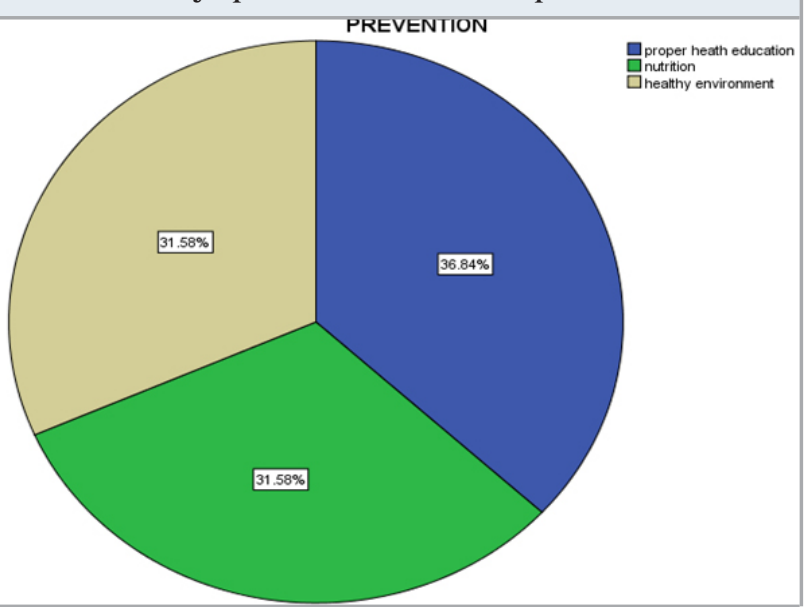


Figure 12: Pie chart shows the age group where blue colour denotes 18-20 years and green colour denotes 20-30 years of age. $61.40 \%$ of the study participants answered they were under the age group 20-30 years.

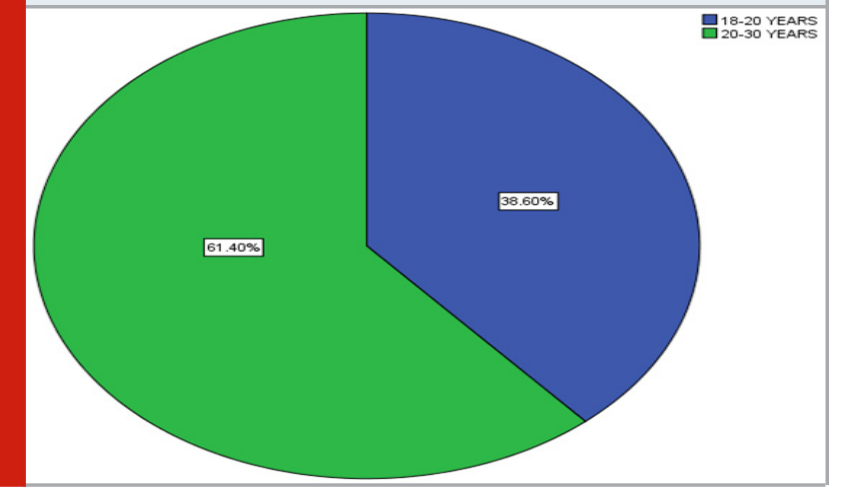

As discussed in previous article women are only aware of the term premature babies but not the complications and consequences caused by them (Scott, Steel 0'Connor and Carr, 2001)Premature babies may need longer or more intense nursery care, medication and sometimes surgery. A study done by Oliveria et al showed that preterm birth is very common in recent years due to many factors which mainly include health complications - Women are not very much aware of the serious problems or complications that arise due to premature babies to them and as well as the mothers (Oliveira et al., 2020). This is well correlated with our study. As recent research has proved that stress is a leading factor contributing to a major reason for preterm birth. This stress can be emotional,financially or anything. So as discussed in previous articles preterm births can be prevented by going to regular health check ups, doing mediation, being relaxed free from stress(Schander et al., 2017). As we all know once a woman is pregnant she can't be given any medications other than recommended by the doctor for her nutrition.But sometimes doctors give corticosteroids, which helps in babies better lung maturity .

It's so clearly known that Preterm babies may or may not suffer lifelong effects such as cerebral palsy, mental retardation, visual and hearing impairments, and poor health and growth. Babies born only a few weeks early (late preterm, 34-36 weeks) often have long-term difficulties such as(Romero, Dey and Fisher, 2014).As discussed in many articles, preterm babies track with full term babies as they start growing up .Most preemies grow up to be healthy kids. They tend to be on track with full-term babies in their growth and development by age 3 or so.Even though baby's early years maybe more complicated than a full-term baby's. Because they're born before they're ready, almost all preemies need extra care(Bosworth and Dobkins, 2013). The limitation of this study was that an equal number of participants can be included with different age groups to get more accuracy in the results. The future scope of this study is that it can be expanded widely to include an equal number of

participants to assess the awareness and knowledge on the Preterm birth and its consequences.

Figure 13: Bar chart showing the comparison of responses between age groups and knowledge on causes of preterm birth. X-axis represents different age groups and Y-axis represents percentage responses for causes of preterm birth. From this chart it was found that the opinion of the both age groups was higher for foetal causes. Majority of the study population aged between 20-30 years were more aware of the causes than the other age group (18-20 years) and the difference is also statistically significant. Chi square test P-value-0.020(<0.05).

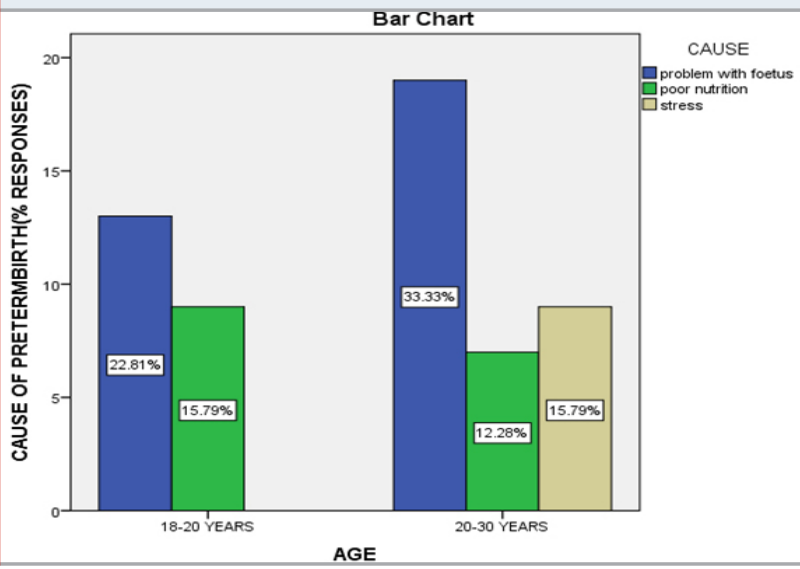

Figure 14: Bar graph depicts the association between age and knowledge on complications it causes due to preterm birth. $\mathrm{X}$-axis represents different age groups and $\mathrm{Y}$-axis represents percentage responses for complications of preterm birth. From this chart it was found that the opinion of the both age groups was higher for maternal complications. Majority of the study population aged between 20-30 years were more aware of the complications of preterm birth than the other age group (18-20 years). However the difference was statistically not significant. Chi square test P-value-0.976 (>0.05) statistically not significant.

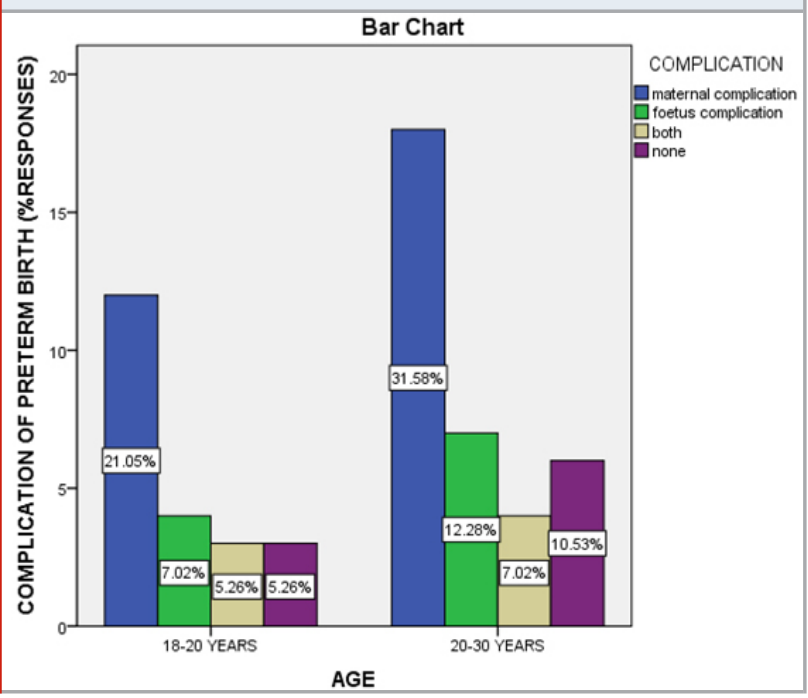




\section{CONCLUSION}

Within the limitations of our study, we conclude that an average of $65 \%$ of the females of the reproductive age group were aware of preterm birth and its causes and complication and the age group 20-30 years females of our study sample were more aware about the causes and complications of preterm birth than the 18-20 years aged group. Further studies can be done to analyse health related problems which can lead to premature babies.

\section{ACKNOWLEDGEMENTS}

The authors would like to thank the study participants for their participation and kind cooperation throughout the study.

Conflict of Interest: The authors declare that there were no conflicts of interest in the present study.

\section{REFERENCES}

Abijeth, B. and Brundha, M. P. (2017) 'Awareness Of Jaundice Among Mothers Of Children Below 10 Years of Age', International Journal of Current Advanced Research, 6( 4), pp. 3326-3328.

Benitz, W. E. (2009) 'Perinatal Outcomes Associated With Preterm Birth at 33 to 36 Weeks' Gestation: A Population-Based Cohort Study', Yearbook of Neonatal and Perinatal Medicine, pp. 12-14. doi: 10.1016/s87565005(09)79097-3.

Bosworth, R. G. and Dobkins, K. R. (2013) 'Effects of prematurity on the development of contrast sensitivity: testing the visual experience hypothesis', Vision research, 82, pp. 31-41.

Brundha, M. P. (2015) 'A Comparative Study-The Role of Skin and Nerve Biopsy in Hansen's Disease', Research journal of pharmaceutical, biological and chemical sciences. Journal of Pharmaceutical Sciences and Research, 7(10), p. 837.

Copper, R. L. et al. (1993) 'A multicenter study of preterm birth weight and gestational age-specific neonatal mortality', American Journal of Obstetrics and Gynecology, pp. 78-84. doi: 10.1016/s00029378(12)90889-3.
Dietze, T. R., Rose, F. F. and Moore, T. A. (2016) 'Maternal variables associated with physiologic stress and perinatal complications in preterm infants', Journal of Neonatal-Perinatal Medicine, pp. 271-277. doi: 10.3233/ npm-16915134.

Dole, N. (2003) 'Maternal Stress and Preterm Birth', American Journal of Epidemiology, pp. 14-24. doi: 10.1093/aje/kwf176.

Goldenberg, R. L. et al. (2009) 'Preterm Birth 1: Epidemiology and Causes of Preterm Birth', Obstetric Anesthesia Digest, pp. 6-7. doi: 10.1097/01. aoa.0000344666.82463.8d.

Iams, J. D. (no date) 'Care for Women with Prior Preterm Birth', Preterm Birth, pp. 115-129. doi: 10.1002/9781444317619.ch11.

Joseph, K. S. et al. (2001) 'Causes and Consequences of Recent Increases in Preterm Birth Among Twins', Obstetrics \&t Gynecology, pp. 57-64. doi: 10.1097/00006250-200107000-00011.

Lisonkova, S. et al. (2016) 'Maternal morbidity and perinatal outcomes among women in rural versus urban areas', CMAJ: Canadian Medical Association journal = journal de l'Association medicale canadienne, 188(1718), pp. E456-E465.

Oliveira, C. et al. (2020) 'Health-related quality of life in neonates and infants: a conceptual framework', Quality of Life Research, pp. 1159-1168. doi: 10.1007/s11136020-02432-6.

Romero, R., Dey, S. K. and Fisher, S. J. (2014) 'Preterm labor: one syndrome, many causes', Science, 345(6198), pp. 760-765.

Schander, J. et al. (2017) 'New strategies to prevent preterm birth', Placenta, pp. 106-107. doi: 10.1016/j. placenta.2017.01.036.

Scott, H. M., Steel 0’Connor, K. O. and Carr, P. A. (2001) 'Evaluation of a Community-Wide Preterm Birth Prevention Program', Canadian Journal of Public Health, pp. 328-330. doi: 10.1007/bf03404973.

Thornton, S. (2008) 'Preterm Birth: Causes, Consequences and Prevention', The Obstetrician \& Gynaecologist, pp. 280-280. doi: 10.1576/toag.10.4.280b.27453.

Wadhwa, P. D. et al. (2011) 'The Contribution of Maternal Stress to Preterm Birth: Issues and Considerations', Clinics in Perinatology, pp. 351-384. doi: 10.1016/j. clp.2011.06.007. 